\title{
Formation of Viologen-containing Organic Monolayer on Si(111) Surface
}

\author{
Dae-Hyun Shin, Bỵung-Gak Yoo, Cheol Min Yoon, Chi-Woo J. Lee, and Kohei Uosaki
}

\author{
Department of Atwanced Materials Chemistr, Korea Unwersit, Jochin'on, Choongnam 339-700. Korea ${ }^{*}$ E-mail: culleeakorea ac.kr" \\ ${ }^{\dagger}$ Phisical Chemistry Laboratory. Division of Chemistry, Graduate School of Science. Hokkaido University . How8, \\ Kita-ku, Sapporo 060, Japan \\ Received October 27. 2006
}

Key Words : Si(11). Viologen, Electrochemistry. ATR-FTIR, Oxygen

Since Linford and Chidsey demonstrated that pyrolysis of neat diacyl peroxides in the presence of hydrogen-terminated single cry'stalline silicon led to the fomation of a denselypacked organic monolayer covalently bonded to the silicon surface. ${ }^{1.2}$ studies on the construction of organic monolayers on silicon surfaces has expanded to develop chemical protection strategies for $\mathrm{Si}$ surfaces ${ }^{3-5}$ and to form metal-organic layer-Si junctions for device applications in nanoelectronics. ${ }^{6.8}$ In this work, we wish to report that silicon surface was functionalized by an organic monolayer with viologen. which was effective for the reduction of molecular oxygen at the silicon surface. We have previously reported electrochemistry of viologens physically as well as chemically selfassembled on electrode surfaces ${ }^{(1)}$ and chemical nodification of light-emitting silicon materials. ${ }^{11}$ Masuda and Uosaki's recent letter ${ }^{12}$ prompted the present work but a more versatile functional viologen with carboxyl group was immobilized via direct $\mathrm{C}$-Si bond formation at the silicon surface in our case and we present the experimental evidences of viologen-containing organic monolayer formed covalently at $\mathrm{Si}(111)$ surfaces by ATR-FTIR and voltammetry.

The parallelogram ATR prism was prepared from phosphorous doped n-type $\mathrm{Si}(111)$ wafers $(1.0-10 \Omega \mathrm{cm})$. which were polished on both sides for the ATR-FTIR measurements as before. ${ }^{13}$ Acetone and DI water were used for rinsing $\mathrm{Si}(111)$ samples in sonication and piranha solution was used for making oxide layer on silicon surfaces. To obtain a hydrogen-terminated $\mathrm{Si}(111)$ surface. the ATR prism was immersed in a $40 \% \mathrm{NH}_{4} \mathrm{~F}$ solution and dried in a flowing nitrogen gas. The sample was then thernally treated with 4-vinylbenzy'l chloride (4-VBC) and 4-propylcarboxylic-4'-bipyridine. which was prepared from 4.4'-bipyridine and bromopropionic acid to produce Si-4-vinylbenżl-1-(2carboxy'lethyl)-4.4'-bipy ridium (Si-4-VB-VCOOH)

ATR-FTIR measurements were performed using a BioRad Excaliber ${ }^{\mathrm{TM}}$ spectrometer equipped with HgCdTe (MCT) detector and home-made sample holder. Ar gas was continuously introduced into the FTIR chamber. The ATR-FTIR spectra were recorded with p- and s-polarization for an oxidized $\mathrm{Si}(111)$ surface as a background. Electrochemical experiments were carried out using an $E G \& G 283$ A potentiostat in a three electrode electrochemical cell. A Ag/ $\mathrm{AgCl}$ electrode. a Pt wire. and the Si(111) substrates were used as a reference. a counter. and a working electrode respectively. The electrolyte solution used was $0.1 \mathrm{M} \mathrm{KCl}$ aqueous

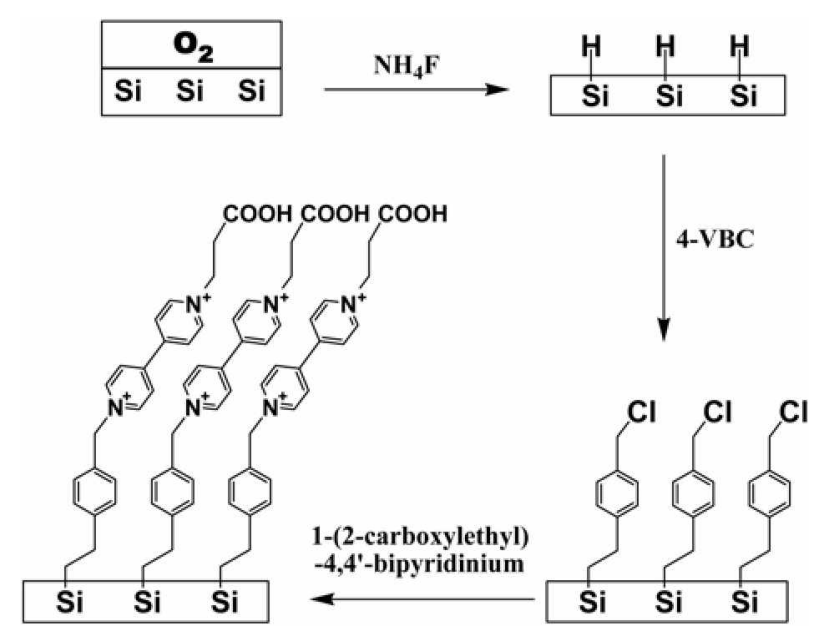

Scheme 1. The synthetic sequence of $\operatorname{Si}(111)-4$-viny lbenzyl-1-(2carbosylethyl-4,4'-bipyridium.

solution. All the potential was quoted against $\mathrm{Ag} / \mathrm{AgCl}$. The preparation sequence of the viologen-containing organic monolayer is shown in Scheme 1.

Figure 1 compares the FTIR spectra of the (a) $\mathrm{H}-\mathrm{Si}(111)$. (b) 4-VBC-Si(111). and (c) Si-4-VB-VCOOH substrates. Two peaks conmonly' seen around $2920 \mathrm{~cm}^{-1}$ and $2850 \mathrm{~cm}^{-1}$ in both (b) and (c) were assigned to the asymmetric and the symmetric $\mathrm{CH}_{2}$ stretching, respectively. ${ }^{1.21+} \mathrm{The}^{\mathrm{i}} \mathrm{CH}_{2}$ bending scissors were found around $1470 \mathrm{~cm}^{-1}$ as the $\mathrm{C}=\mathrm{O}$ stretching around $1650 \mathrm{~cm}^{-1}$. A broad peak above $3200 \mathrm{~cm}^{-1}$ was assigned to $\mathrm{OH}$ stretching. The peaks of $\mathrm{CH}$ stretching vibrations of the benzene ring were observed between 30000 $\mathrm{cm}^{-1}$ and $3100 \mathrm{~cm}^{-1}$. As the hydrogen-terminated $\operatorname{Si}(111)$ was reacted with 4-vinylbenzyl chloride, a sharp Si-H peak at $2108 \mathrm{~cm}^{-1}$ disappeared and new peaks were found around $3040 \mathrm{~cm}^{-1} .2920 \mathrm{~cm}^{-1} .2850 \mathrm{~cm}^{-1}$ and $1470 \mathrm{~cm}^{-1}$. indicating that $4-V B C$ was successfully immobilized at $\operatorname{Si}(111)$ surface via Si-C covalent bond. When $\mathrm{Si}(111)-4-\mathrm{VBC}$ substrate was further treated with 4-propylcarboxylic-4'-bipyridine additional peaks were observed around $1650 \mathrm{~cm}^{-1}$ for $-\mathrm{C}=\mathrm{O}$ stretching and above $3200 \mathrm{~cm}^{-1}$ for $-\mathrm{O}-\mathrm{H}$ stretching. suggesting that covalent binding of 4-propylcarbosylic-4'-bipyridine was achieved at the $\mathrm{Cl}$ position of 4-VBC-Si(111). Although it has been previously noted that the O-H stretch. which had disappeared in the hydrogen-terminated $\mathrm{Si}$ surface. largely returns when straight alkyl monolayer was formed at Si(111) surface. ${ }^{1}$ no similar spectral features were 


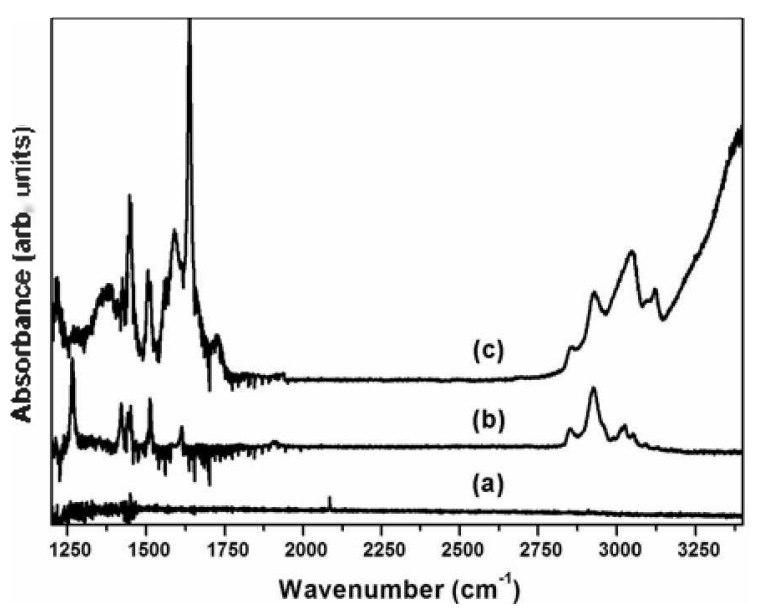

Figure 1. ATR-FTIR spectra of (a) H-Si( 111), (b) 4-VBC-Si(111), and (c) $\mathrm{Si}-4-\mathrm{VB}-\mathrm{VCOOH}$ substrates.

seen in the present work. Although the $\mathrm{OH}$ or oxide was discussed to be formed based on the difference in the nearest-neighbor distance between silicon atoms on the $\mathrm{Si}(111)$ surface $(3.84 \mathrm{~A})$ and alkyl chains (diameter $4.6 \mathrm{~A}){ }^{1}$ the formation of $\mathrm{OH}$ or oxide at silicon sufface may occur depending on the degree of packing of monolayer fomed. We note that it was recently reported that the initial electronic properties and structure of the interface were found to be long-lasting only when the monolayer surface coverage was greater than 0.42 . leaving intermolecular channels narrower that $2.82 \mathrm{~A}$. the diameter of water. ${ }^{4}$ We believe that we formed such a high-quality 4 -VBC monolay'er that $\mathrm{OH}$ stretching was not seen in Figure 1B

Figure 2 shows cyclic voltammograms of 4-VBC-Si(111) electrode (a). and the first redox process of viologen $(2+/+)$ at Si-4-VB-VCOOH in the absence (b) and presence (c) of molecular oxygen in $0.1 \mathrm{M}$ potassium chloride electrolyte solution. The small background current as well as ideal polarizable behavior in the wide potential range from 0 to $-1.6 \mathrm{~V}$ versus silver-silver chloride reference electrode observed at $\mathrm{Si}(111)-4-\mathrm{VBC}$ indicates that the silicon electrode was completely covered with the well-packed organic monolayer having little holes for possibility of water or electrolyte penetration. When viologen remained to be covalently bonded at the well-packed 4-VBC-Si(111) surface. the silicon electrode showed the prominent reduction and corresponding oxidation peaks at $-0.54 \mathrm{~V}$ and $-0.40 \mathrm{~V}$. respectively, for the redox probe at the scan rate of $10 \mathrm{mV} / \mathrm{s}$. The peak separation became larger as the scan rate was increased. indicating that charge transfer kinetics was involved with the surface electrochemical process. Much larger cathodic current without any corresponding oxidation peak flowed when the identical experiment was performed in the presence of molecular oxygen. suggesting that the reduced viologen catalyzed reduction of molecular oxygen at the silicon surface. We note that the catalytic activation current of molecular oxygen was observed at silicon surface. which is known uncontrollably reactive toward oxygen. and that the peak potential in the presence of oxygen was close to that of the cathodic peak potential of viologen in the absence

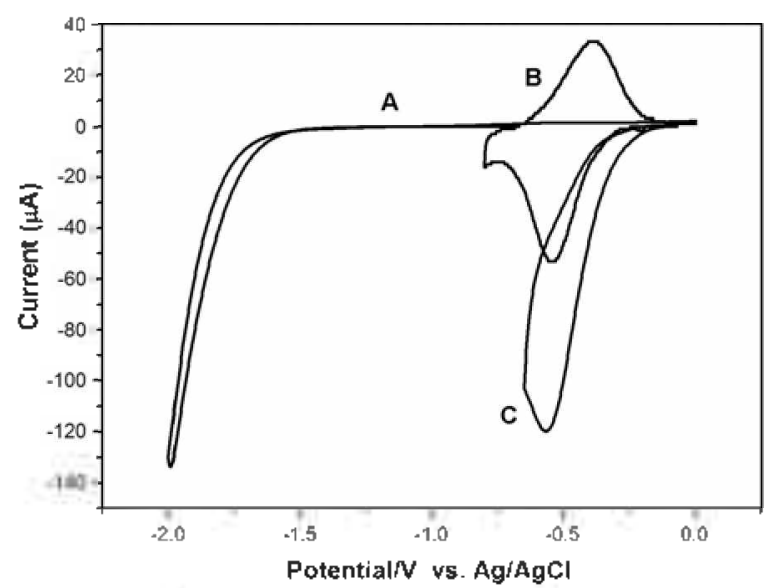

Figure 2. Cyclic voltammograms of 4-VBC-S $(111)$ electrode under argon atmosphere (a), and the first redox process of viologen $(2+1$ $+j$ at $\mathrm{Si}-4-\mathrm{VB}-\mathrm{VCOOH}$ in the absence (b) and presence (c) of molecular oxy gen in $0.1 \mathrm{M}$ potassium chloride electrolyte solution. Scan rate; $10 \mathrm{mV} / \mathrm{s}$.

of oxygen. These would not be possible unless the bimolecular reaction rate between the reduced viologen bound at the silicon surface and oxygen in solution was extremely fast as was the case with other electrodes. ${ }^{9}$ The chemically modified silicon electrode may be profitably usable for oxygen sensing. In addition. the carboxyl group at the end of the functionalized viologen on silicon surface can be further derivatized with $-\mathrm{NH}_{2}$ group, for example, in biological molecular system. Work is in progress toward this direction.

Acknowledgement. This work was funancially supported by Korea Science and Engineering Foundation (F01-2005000-10127-0) and BK21 Material Chemistry in 2006.

\section{References}

1. Lintord. M. R.: Chidsey. C. E. D. J. Am. Chem. Soc. 1993. 1/5. 12631

2. Linford. M. R.: Fenter, P.: Eisenberger, P. M.: Chidsey. C. E. D. $d$. Am. Chem. Soc. 1995. 117,3145.

3. Webb, L. J:- Nemanick, J.: Biteen, J. S.: Knapp, D. W.: Michalak. D. J.; Traub, M. C. Chan, A. S. Y.; Brunschwig. B. S.: Lewis, N S. J. Phys. Chem. B 2005, 109. 3930 .

4. Gorostiza. P.: Villeneuve. C. H.: Sur1. Q. Y.: Sanz. F.: Wallart. X.: Boukherroub. R.: Allongue. P. J. Phw Chem. B 2006. 1]0. 5576.

5. Asanuma. H.: Noguchi. H.: Uoraki. K.: Yu. H.-Z. J. Phys. Chent $B \mathbf{2 0 0 6}, 110,4892$.

6. Seitz. O.: Bocking. T; Salomon, A.: Gooding. J. J; Cahen, D Langmir 2006. 22.6915

7. Richter. C. A.: Hacker. C. A.: Richter L. J. J. Phs Chem. B 2005 109.21836 .

8. Faber. E. I.: de Smet. L. C. P. M.: Olthuis. W. Zuilhof. H.: Sudholter. E. J. R.: Bergueld, P; van der Berg, A. Chem. Phys. Chem. 2005. 6. 2153

9. Lee. C.-W. Jang. J-M: Shin, D.-S. Bull. Korean Chem. Soc. 1990. 11. 170. Bull. Kowan Chent. Sox. 1994. 15. 563.

10. Lee. C.-W.: Oh. M.-K. Bull. Korean Chent Soc. 1994. 15. 339.

11. (a) Lee. C.-W. Kim. D.-I.: Oh. M.-K. Bull Korean Chent Soc. 1993. 14, 162. (b) Kim, D.-I. Lee, C.-W. Bull Korean Chem. Soc 1995. 16,1019

12. Masuda. T.: Uosaki. K. Chem. Lett. 2004, 33,788.

13. Bae. S.-E.: Lee. J-S.: Lee. I-C.: Song. M.-B.: Lee. C.-W. J. Bull. Korean Chem. Soc. 2005, 11. 1891

14. Uosaki, K.; Quayum. M. E.: Nihonvanagi, S:; Kondo. T. Lamgnui $2004,20,1207$ 